\title{
Rei morto, rei posto? As lutas pela sucessão de Pierre Bourdieu no campo acadêmico francês*
}

\author{
Angela Xavier de Brito \\ Centre Nacional de la Recherche Scientifique (CNRS) \\ Centre d'Études sur les Liens Sociaux (CERLIS) \\ U niversité de Paris V, Faculté de Sciences Humaines et Sociales
}

\author{
O que dá pra rir, dá pra chorar \\ questão só de peso e medida, \\ questão só de hora e lugar, \\ pois tudo são coisas da vida... \\ Billy Blanco, Canto chorado
}

A perda daquele que todos, aliados e detratores, consideram unanimemente o maior sociólogo atual de língua francesa deixou um grande vácuo intelectual, cujo preenchimento não se fará sem dificuldades. A celebridade de Pierre Bourdieu ultrapassou em muito as fronteiras do campo acadêmico. Seu prestígio pode ser calculado quando se sabe que, desde a morte de Sartre, a grande imprensa francesa não dedicava suas manchetes a uma personalidade dessa esfera. Não é minha intenção deter-me sobre o conteúdo das mensagens veiculadas pelos jornais. Se a atual conjuntura francesa permite dar maior visibilidade aos cientistas

* Agradeço a Luiz Antonio Cunha - amigo e colega de muitos anos, com quem partilho outras coisas além do amor à sociologia - as sucessivas leituras e os comentários feitos a este artigo. cuja ação acadêmica lhes abriu as portas do campo político, convém assinalar que, como era de se esperar, esse acontecimento foi tratado do ponto de vista do senso comum. Foram publicadas entrevistas apressadas, com frequiência sob a influência da emoção do momento, bibliografias incompletas, senão mal hierarquizadas ou errôneas. Houve confusão entre sua obra acadêmica e sua obra política. Professores e pesquisadores agitaram-se - Bourdieu despertou paixões e ódios, mas nunca deixou ninguém indiferente. Prova disso são as homenagens mais ou menos bem-sucedidas, os comentários positivos ou negativos à sua teoria, os números de revistas especializadas, as alusões irônicas disfarçadas nas entrevistas, a demonstração mais ou menos velada dos interesses em jogo no tipo de crítica feito a seus trabalhos, os mea culpa e os ressentimentos que emergem entre os que participaram de seu círculo de amigos ou de "adversários íntimos" (Bourdieu, 1988, p. 70). As estratégias de luta vão afinando-se à medida que o campo de batalha se delineia melhor.

Neste artigo, não pretendo tratar do homem Pierre Bourdieu, com as qualidades e as fraquezas que cons- 
tituem simultaneamente todo ser humano, segundo o espírito dialógico de Edgar Morin (2001). Procurarei analisar as transformações que sua morte está acarretando no campo da sociologia francesa para preencher o vazio deixado no pensamento sociológico francês. Ora, é difícil uma posição tão significativa ficar muito tempo sem ser preenchida. Assim, os pretendentes à sua sucessão atropelam-se simbolicamente nos degraus do Collège de France, ${ }^{1}$ cada rede sustentando com maior ou menor ênfase seu candidato. Antes, porém, deve-se estabelecer uma distinção entre seu espólio material e sua herança intelectual. ${ }^{2}$ Tentarei resituar para fins analíticos, em um primeiro momento, a transmissão do capital simbólico acumulado na esfera institucional, passando em seguida a descrever os debates teóricos travados em torno da obra deste grande sociólogo.

Apesar de se reger pelas normas da "sociedade de corte" (Elias, 1985), o campo da sociologia está longe de ser uma monarquia. O primogênito de Bourdieu, Emmanuel, não ocupará seu lugar por direito divino. Talvez por ter compreendido que o sobrenome lhe traria mais dissabores do que vantagens, bem antes da morte de seu progenitor - depois de ter escrito um livro que passou despercebido -, já tinha enveredado por uma via profissional na qual o prestígio paterno não embaçaria o seu, mas em que o capital cultural e social transmitido por via familiar seria igualmente ativo - o cinema.

Como todo paterfamilia previdente, Pierre Bourdieu já tinha disposto de pelo menos uma parte do seu espólio, dividindo-o entre aqueles que ficaram com ele até o fim. Assim, Patrick Champagne recebeu a direção do Centre de Sociologie Européenne. Resta saber a quem irá a direção da revista editada

\footnotetext{
${ }^{1} \mathrm{O}$ último cargo ocupado por Bourdieu foi o de professor do Collège de France.

${ }^{2}$ Agradeço a Afrânio Garcia a disponibilidade e a gentileza com que me transmitiu informações e comentários sobre a equipe de Bourdieu.

${ }^{3}$ Trata-se de Emmanuel Bourdieu, Le savoir faire. Contribution à une théorie dispositionnelle de l'action, Paris: Seuil, 1998.
}

por Bourdieu - as Actes de la Recherche en Sciences Sociales. Instrumento que ocupa uma posição fronteiriça entre o espólio e a herança, sem comitê de redação que garanta sua estabilidade, pode-se pensar que a reputação desta publicação não será talvez a mesma no futuro. Seu estatuto científico dependia em grande parte do carisma de seu criador e, como diz o próprio Bourdieu (1984), esta é uma das razões pelas quais o capital simbólico não se transmite por herança.

$\mathrm{Na}$ escolha do sucessor, uma questão pode ser colocada: teria Bourdieu se comportado sem a reflexividade que preconiza? Teria ele cedido à inexorabilidade da "dominação masculina" que descreve? Parece-me que as "recompensas" à fidelidade foram feitas sem nenhuma atenção aos trabalhos efetivamente realizados ou às qualidades intelectuais dos sucessores. Os que conhecem bem o funcionamento de sua equipe a mostram como essencialmente baseada em mulheres - e, atualmente, apoiada sobre um tripé feminino intelectualmente relevante: Francine MuelDreyfus, Odile Henry, Gisèle Sapiro. No entanto, nenhuma delas foi apontada para os cargos de prestígio. Monique de Saint-Martin já se tinha dado conta disso há algum tempo, o que talvez explique sua transferência do Centre de Sociologie Européenne, onde trabalhou quase toda sua vida, para o Laboratoire des Mouvements Sociaux. ${ }^{5}$

Isso relança o problema de quem ocupará a posição de herdeiro intelectual e teórico de Pierre Bourdieu no campo da sociologia francesa. Não se trata de um lugar qualquer de mais um sociólogo especializado neste ou naquele tipo de sociologia - no caso, a sociologia da educação, objeto que atraiu com freqüência a atenção de Bourdieu sem esgotar seu alcance teórico. É interessante, no entanto, notar que certos sociólogos se apressam a reduzi-lo a esse estatuto (Dubet, 1998) - talvez por poder assim melhor justificar o direito a também se incluir no campo dos herdeiros?

\footnotetext{
${ }^{4}$ Alusão ao título de um de seus livros: La domination masculine, Paris, Seuil, 1998.

${ }^{5}$ Equipe de pesquisa da Ecole de Hautes Etudes en Sciences Sociales (EHESS), atualmente dirigida por Louis Quéré.
} 
Suceder Bourdieu não é uma tarefa qualquer. Trata-se de tomar o lugar - por refutação ou por elaboração crítica - do único intelectual francês contemporâneo capaz de reivindicar a construção de uma teoria bastante geral para comportar até mesmo elementos de universalidade, desde que respeitadas as regras da homologia quanto aos objetos analisados. Nesse cenário supostamente mais democrático, porque depende das qualidades pessoais e profissionais e da construção da carreira de cada pretendente, quem são os candidatos de direito? Que programas defendem? Que legitimidade têm para herdar a posição reclamada? Qual sua capacidade de reconhecer a complexidade da obra de Bourdieu e, assim, dar-lhe continuidade? Quem será capaz de enveredar por um caminho que contribua ao caráter cumulativo da sociologia enquanto ciência?

\section{As forças presentes nas lutas sucessórias dentro do campo acadêmico}

Segundo o próprio Bourdieu, o estado do campo de uma disciplina depende das lutas que diferentes grupos e pessoas com diversos status travam em seu seio, cujos interesses serão forçosamente distintos. Posso distinguir grosso modo três tendências no campo da sociologia francesa, no que se refere à sucessão de Bourdieu.

Uma das orientações à sua sucessão compõe-se dos que seguem sua teoria, aplicando-a a objetos que lhes são próprios. Esses epígonos, em geral, acompanharam Bourdieu em seu périplo intelectual, contribuíram para construir o prestígio de sua equipe de pesquisas na EHESS, ${ }^{6}$ forneceram em maior ou menor grau as bases empíricas imprescindíveis para testar sua teoria. Para eles, "desapareceu o maior sociólogo do século XX" (Pinçon \& Pinçon-Charlot, Le Monde, 25/1/2002), sua morte foi "uma perda intelectual considerável para as ciências sociais" (Muel-Dreyfus, $L e$ Monde, 25/1/2002). Talvez por aplicarem a reflexividade recomendada pelo próprio Bourdieu na constru-

\footnotetext{
${ }^{6}$ Trata-se do Centre de Sociologie Européenne na EHESS.
}

ção de suas carreiras, os testemunhos desses sociólogos no momento do luto orientaram-se mais no sentido de uma apologia quanto à potência explicativa do seu quadro teórico. "Contentamo-nos em pôr em ação seu sistema teórico com muito entusiasmo, a torná-lo vivo no seio da grande burguesia. Devemos-lhe tudo. Seu sistema era uma síntese brilhante, eficaz, de tudo o que se passou antes em sociologia e em filosofia" (Pinçon \& Pinçon-Charlot, Le Monde, 25/1/2002). Nem por isso todos os estudos produzidos por essa corrente são menos inventivos do que outros. Pode-se citar como exemplo o trabalho original sobre as elites francesas intitulado Dans les beaux quartiers (Pinçon $\&$ Pinçon-Charlot, 1989), que deu a seus autores uma reputação internacional. Deve-se reconhecer, porém, que sua contribuição à disciplina se fez antes por meio da construção rigorosa do objeto do que a partir de inovações no campo teórico ou metodológico.

$\mathrm{Na}$ verdade, o principal risco que correm os grandes homens - Marx e Lacan são um bom exemplo provém dos seguidores acríticos que, em prova equivocada de respeito, transformam sua contribuição em algo rígido, imutável, a ser conservado como peça de museu. Conceitos cuja capacidade primeira é interpretar o real são congelados em um dado espaço-tempo e tornam-se aistóricos. Todas as variações de uma obra inovadora, inscrita em um dado momento da história da sociologia na qual as exigências sociais e teóricas eram diferentes, na qual o paradigma dominante era outro, perdem-se. Longe de mim afirmar tão taxativamente quanto Luc Boltanski que isso existe de fato: "Como para o lacanismo, havia ao redor dele uma espécie de grupinho de seguidores auto-proclamados funcionando como seita política e servindo-se deste pertencimento para um empurrãozinho" (Boltanski, Le Monde, 25/1/2002).

Mas certamente não é entre os que cristalizaram sua teoria que encontraremos o sociólogo que poderá sucedê-lo. Se acreditamos que o caráter histórico e cumulativo da ciência é mais importante que seu movimento pendular - que recobre e oculta todos os movimentos paralelos, subjacentes, que contribuirão ao parto de novos paradigmas -, o que importa neste campo são simultaneamente o processo de acumula- 
ção científica e as maneiras pelas quais ela se dá. Se a ciência é reconhecidamente mais uma questão de redes do que de personalidades, podemos crer que cada pesquisador, conhecido, pouco conhecido ou desconhecido, aporta sua contribuição, maior ou menor, mais ou menos original, para sua construção, mas em diferentes níveis (Xavier de Brito \& Leonardos, 2001). Talvez seja, antes de tudo, necessário resgatar o trabalho coletivo realizado no seio do Centre de Sociologie Européenne. É para esta dimensão que Francine Muel-Dreyfus (Le Monde, 25/01/2002) chama a atenção, ao dizer que "é importante mobilizar-se para continuar este trabalho". Talvez as críticas e autocríticas $^{7}$ dos que trabalharam nesta equipe até um dado momento, abandonando-a depois, adquiram novos contornos quando se pensa que, se o princípio do debate ou da discussão contraditória não faz parte da cultura escolar francesa (Collet, 1997), ela integra ainda menos a cultura dos mandarins.

Por essa razão, Bourdieu não inspirava apenas fidelidades e adesões. Sua aspiração absoluta de construir uma "escola", o desejo de se firmar como autoridade inconteste no campo da sociologia francesa, senão mundial, fazia com que os pesquisadores formados em sua equipe se sentissem atados, constrangidos por uma camisa-de-força. Isso os levava à grande decisão: ficar na equipe sem dar largas às contribuições científicas que sentiam brotar dentro de si ou tentar a aventura por conta própria na selva da universidade ou do CNRS, sem a proteção do "grand patron", freqüentemente em oposição feroz às mesmas idéias para as quais não tinham podido dar sua contribuição. Vários pesquisadores se encontram neste caso, cuja obra

\footnotetext{
${ }^{7}$ Autocrítica de Monique de Saint Martin realizada por ocasião de uma sessão de seu seminário sobre a noção de campo na trajetória das elites em fevereiro de 2002. Essa pesquisadora diz que tanto ela quanto os demais membros da equipe poderiam talvez ter-se mostrado mais aguerridos no que se refere à introdução de elementos dinâmicos na teoria que emanou da equipe.

${ }^{8}$ Termo usado na França para designar os "mandarins", os que desfrutam de alto poder, freqüentemente arbitrário, no sistema universitário.
}

constitui parte apreciável da sociologia francesa. A negação quase epidérmica de tudo o que se refere à sua antiga integração na equipe de Bourdieu leva alguns dos que ai trabalharam a se situar na outra extremidade do continuum teórico. Exemplos disso são a adesão de Jean-Michel Chapoulie $(1984,2000,2001)$ às teorias interacionistas, particularmente à Escola de Chicago, e a inscrição de Luc Boltanski (1990) na etnometodologia e na "virada lingüística". Mas o paradoxo reside no fato que, se eles podem elevar sua voz no campo da sociologia, isto se deve pelo menos em parte à excelente formação de que se beneficiaram no Centre de Sociologie Européenne, às suas prévias publicações junto com o próprio Bourdieu, que contribuíram para modelar suas carreiras. Deve-se considerar que ao menos este primeiro aspecto é reconhecido pelos que crêem ter deixado Bourdieu detrás de si: "O que retenho dele é sua qualidade de professor, nos anos 60-70" (Boltanski, Le Monde, 25/1/2002). No entanto, aqueles que se deixaram levar por um excesso de amargura crítica - a exemplo de Janine Verdès-Leroux (1998) - perderam legitimidade aos olhos da comunidade científica.

É difícil estabelecer a fronteira entre a crítica respeitosa e construtiva e o desejo de ultrapassar a envergadura teórica da obra que se pretende criticar. Entre as pretensões de destronar o rei ou de prolongar sua obra, a distância é imensa e a ambição em jogo mais ou menos desmesurada. Finalmente, a oposição a Pierre Bourdieu pode revelar-se uma poderosa alavanca em direção a um maior prestígio e legitimidade científicos. Os partidários de uma postura de "respeito crítico" explícito são ainda poucos: ${ }^{10}$ eles são, em geral,

\footnotetext{
${ }^{9}$ Uma simples análise de conteúdo da bibliografia dos que têm atualmente uma visão reducionista da teoria de Bourdieu revela que, até uns 15 anos atrás, eles a adotavam plenamente. Dessa maneira, a crítica a Bourdieu reveste o aspecto de acerto de contas consigo mesmo. Comparar, por exemplo, as teorias subjacentes ao artigo escrito em conjunto por Pierre Bourdieu e Luc Boltanski, Le titre et le poste (1975), com as obras atuais deste pesquisador.

${ }^{10}$ Alusão ao título do artigo de Philippe Corcuff (2002) no número especial de Sciences Humaines consagrado a Bourdieu.
} 
pessoas afastadas do jogo de lealdades pessoais para com o autor, que tentam se impor através da construção de uma teoria própria assentada em parte sobre os conceitos fundamentais forjados por Bourdieu, seja prolongando seu alcance, seja propondo sua complementação ou substituição. Esses pesquisadores, que já têm carreira própria, assim como seu próprio grau de prestígio e de reconhecimento, podem permitir-se reconhecer o status da teoria de Bourdieu no contexto da sociologia francesa e mundial, "dando a César o que é de César" na construção de uma sociologia contemporânea, conscientes de que essa atitude não diminui em nada sua própria obra - ao contrário, a realça.

Bourdieu construiu uma teoria da sociedade como um mercado onde circulam bens econômicos e simbólicos, cujos conceitos centrais são os de campo, de habitus e de capital sob suas diversas formas (econômica, cultural, social, simbólica). Não se trata absolutamente de conceitos isolados - embora sua potência faça que sejam empregados dessa maneira dentro de outros quadros teóricos. Eles são estreitamente interligados e articulam-se de modo coerente no contexto de uma mesma teoria explicativa. $\mathrm{O}$ que se observa, porém, no momento das lutas pela sucessão de Pierre Bourdieu no campo acadêmico é que mesmo os pretendentes que fazem obra teórica mais ampla partem, de modo geral, de um ou outro conceito e não se fundam sobre o conjunto da teoria. Nas páginas seguintes, analisarei a contribuição crítica dos que me parecem ser os principais atores em concorrência: Bernard Lahire, Jean-Claude Kaufmann e Gisèle Sapiro.

\section{0 conceito de habitus}

Uma das noções mais contestadas de Bourdieu, no sentido em que retira toda capacidade de iniciativa do indivíduo e contribui mecanicamente para a reprodução social, é o conceito de habitus. Penso que as críticas que se limitam a apontar-lhe o reducionismo como a de Jeffrey Alexander (2000) - não resistem a uma leitura mais profunda da obra de Bourdieu. Não seria de todo absurdo dizer que as interpretações de certos autores americanos nessa questão se originam de uma divergência cultural entre a França e os Estados Unidos, onde o peso do indivíduo na sociologia sempre foi mais forte.

$\mathrm{Na}$ verdade, a idéia de Bourdieu segundo a qual o habitus é uma "matriz de disposições" ou melhor um "sistema de disposições duráveis e transponíveis, estruturas estruturadas predispostas a funcionar como estruturas estruturantes, ou seja, como princípios geradores e organizadores de práticas e de representações" (Bourdieu, 1980) - e não um conjunto de dispositivos rígidos - parece atribuir-lhe certo dinamismo, capturar a idéia subjacente de processo e a influência dos contextos. Lahire (1998), por exemplo, considera que "a teoria da prática e do habitus desenvolvida por Pierre Bourdieu [é] uma das orientações teóricas mais instigantes e mais complexas das ciências sociais". O habitus descrito por Bourdieu, no entanto, é sobretudo um habitus de classe, variável sociológica dominante na época em que ele lançou as bases de sua teoria. Ele o diz textualmente: "A cada classe de posições corresponde uma classe de habitus, produzidos pelos condicionamentos sociais associados à condição correspondente [...] unidos entre eles por uma afinidade de estilo" (Bourdieu \& Wacquant, 1994, p. 23). Atualmente, vários sociólogos tomaram consciência de que a origem ou o pertencimento a esta ou aquela fração de classe ou categoria socioprofissional não esgota as possibilidades de classificação dos indivíduos. ${ }^{11}$ A idéia de que "todo corpo individual [está] mergulhado em uma pluralidade de mundos sociais [e] submetido a princípios de socialização heterogêneos, por vezes contraditórios, que incorpora" (Lahire, 1998) sugere que o indivíduo pode desenvolver uma pluralidade de habitus segundo as experiências que adquire.

A noção por mim desenvolvida - de habitus de migrante $-{ }^{12}$ tem seu núcleo justamente centrado nas

${ }^{11}$ A este respeito, consultar os anais da jornada de estudos intitulada "Contextualizar a sociologia compreensiva: o problema da origem e do meio social", organizada pelo CERLIS, em 26 de janeiro de 2001.

${ }^{12}$ Referência a meu artigo, citado na bibliografia como Xavier de Brito (s.d.), submetido à publicação nas revistas Lien Social et politiques e Sociétés contemporaines. 
experiências cotidianas semelhantes vividas pela maior parte dos indivíduos que, por uma ou outra razão, se vêem submetidos a situações de deslocamento no espaço ao longo de sua trajetória. No caso destas populações, seus habitus funcionam, segundo o contexto e o momento, como reações de defesa contra uma situação que lhes parece hostil ou como fonte de recursos para proceder às reformulações necessárias à gestão do contexto em que se encontram (Xavier de Brito, s.d.). Finalmente, os trabalhos atuais tendem a considerar que o conceito de cultura nada tem de monolítico, que as pessoas "aceitam, rejeitam, transformam sua herança cultural" (Singly, 1996; Vasquez-Bronfman, 2000) segundo os contextos nos quais se encontram, abrindo "um espaço de iniciativa no próprio seio da conformidade para com a norma" (Rude-Antoine, 1999).

\section{Habitus e disposições}

Os candidatos à sucessão de Bourdieu devem alinhar-se pelas idéias gerais propostas pelo autor, ultrapassá-las ou refutá-las, sobretudo no sentido de propor outra teoria igualmente geral e abrangente, possivelmente de maior poder operacional e explicativo.

Deste ponto de vista, ainda sem entrar no mérito da validade de sua proposição, Bernard Lahire é um dos melhores candidatos. Sua proposta, bastante ousada, afeta a cultura dos sociólogos franceses. Ao analisar sua obra, não devemos recair no erro em que incidem alguns críticos de Bourdieu, colocando ao mesmo nível obras produzidas em épocas diferentes e com diferentes status. A arqueologia das proposições de Lahire, por mais recentes que essas sejam, mostra o caminho já percorrido por esse jovem professor da Ecole Normale Supérieure. A primeira versão do projeto de Lahire é tímida e ainda não tem pretensões a ser um projeto global. No livro L'homme pluriel (1998), resultante de seu ano sabático nos Estados Unidos, Lahire faz algumas propostas teóricas que apontam em direção ao caráter plural de uma sociologia das disposições e reconhece que o campo dessa disciplina se abre a novas exigências metodológicas.
Na obra coletiva que coordena no ano seguinte cujo título é em si bastante sugestivo - Bernard Lahire preconiza a elaboração de "uma sociologia psicológica". ${ }^{13}$ É necessário conhecer bem o campo da sociologia francesa para dar-se conta da iconoclastia desses propósitos. Essa disciplina foi construída por Durkheim para opor-se simultaneamente à psicologia e às correntes evolucionistas da etnologia no século XIX (Hess e Xavier de Brito, 1999; Kaufmann, 2001). A divisão do trabalho assim estabelecida entre sociólogos e psicólogos manteve-se de maneira estrita até meados dos anos de 1980. Durante esse período, o indivíduo não era considerado um objeto sociológico (Bateman-Novaes, 1986); noções como representações, imaginário, identidade etc. eram julgadas ilegítimas e podiam descaracterizar um artigo pretensamente sociológico. Os trabalhos de Goffman, apesar de traduzidos para o francês desde os anos de 1970, eram ignorados pelos membros dessa comunidade porque as interações face a face não tinham lugar na sociologia francesa. $\mathrm{O}$ espírito de ciência positiva que dominava essa disciplina desde o início do século XX se questionava sobre seu destino caso ela tomasse como objeto o indivíduo em sua múltipla complexidade pessoal em detrimento da análise dos mecanismos da ação social (Simiand, 1903). Apenas o enfraquecimento dos paradigmas dominantes a partir de 1985 abriu-lhes as portas da cidade sociológica. É possível que a proposição de Lahire tenha recolhido ecos desfavoráveis: os mitos e os rituais de uma comunidade, seja ela sociológica ou outra qualquer, são extremamente resistentes à mudança. O fato é que em Portraits sociologiques, um de seus livros mais recentes, Lahire não mais menciona explicitamente a contribuição da psicologia a seu

${ }^{13}$ Refiro-me ao artigo "De la théorie de l'habitus à une sociologie psychologique" em Bernard Lahire (1999).

${ }^{14}$ Erwin Goffman, sociólogo da chamada Escola de Chicago, nos Estados Unidos, cujas teorias se inspiravam no interacionismo simbólico de G.H. Mead. Sua principal obra, intitulada La mise en scène de la vie quotidienne, foi publicada em 1974 pelas Editions de Minuit, na coleção Le sens pratique, dirigida por Bourdieu. 
projeto. O preâmbulo fala apenas no desenvolvimento de uma "sociologia das propriedades disposicionais e contextuais" que permitiria a "apreensão da variação social dos comportamentos individuais segundo os contextos de ação", na medida em que o indivíduo é "definido pelo conjunto de suas relações, engajamentos, pertencimentos e propriedades" (Lahire, 2002a, p. 2), em que se opõem, se combinam, se articulam harmoniosamente ou se contradizem os diversos elementos e dimensões de sua cultura.

Bernard Lahire utiliza a metáfora do "social dobrado ou desdobrado" para configurar a complexidade da realidade social. O social desdobrado corresponde à versão abstrata das singularidades individuais dentro de certas regularidades e invariantes sociais e históricas, enquanto a vertente dobrada é a parte social que todo indivíduo tem incorporada dentro de si, que se apresenta "sob a forma de combinações nuançadas e concretas das propriedades contextuais e disposicionais" (Lahire, 2002a, p. 3). Nesse sentido, ele não propõe a substituição de um tipo de visão sociológica por outra, mas sua harmonização no sentido de melhor apreender a complexidade social, que inclui necessariamente o indivíduo.

Nesse último tema, ele converge com outro pretendente, senão diretamente à sucessão de Bourdieu, pelo menos ao estrelato sociológico. Jean-Claude Kaufmann - diretor de pesquisa do CNRS e membro do CERLIS - propõe, por sua vez, uma sociologia do indivíduo apreendida a partir não do conceito de habitus segundo Bourdieu, mas do de hábito (habitude em francês), cujas raízes datam de Aristóteles.

Jean-Claude Kaufmann vê-se como sucessor não de Bourdieu, mas de Elias (1991) - que é também claramente uma das fontes de Bourdieu, como o confirma Touraine (2002) - nessa construção teórica que visa analisar o indivíduo como um processo. Segundo Kaufmann (2001, p. 17), isso "implica uma verdadeira revolução das estruturas habituais de nosso pensamento". É nesse sentido que ele se propõe a "salvar o que se pode salvar do habitus de Bourdieu contra o próprio Bourdieu" (Kaufmann, 2001, p. 133).

Na obra Ego. Pour une sociologie de l'individu
(Kaufmann, 2001, p.105-106), o conceito de hábito é “decisivo para superar as oposições material/ideal, objetivo/subjetivo, coletivo/individual, determinismo/liberdade" - tarefa indispensável à construção de uma sociologia contemporânea. Kaufmann (2001) insiste em seu caráter de "esquema de mediação e de comutação", o que o torna um operador eficaz da passagem entre essas categorias opostas. No contexto desse debate, o autor tenta demonstrar como o habitus, segundo Bourdieu, diverge do sentido original do hábito à medida que perde essa característica de intermediação, apesar de aspirar a ela. Kaufmann distingue duas teorias distintas do habitus, na obra de Bourdieu. A primeira funda-se em "um modelo teórico circular e totalizador" (Kaufmann, 2001, p. 139), em que o habitus é um sistema de princípios geradores e organizadores de práticas e de representações, segundo a própria definição de Bourdieu (1980). Na segunda teoria, "a dinâmica da comutação dá lugar a uma cartografia detalhada e um pouco estática do espaço social" porque leva em conta os campos. Nesse contexto, o habitus "aparece mais como um comutador passivo do que um comutador ativo", na medida em que "através dele, a estrutura que o produz governa a prática". Toda pretensão à circularidade é assim abandonada, porque "as estruturas objetivas determinam os habitus que por sua vez determinam as práticas" (Kaufmann, 2001, p. 140 e ss.).

Os pensamentos de Bernard Lahire e de JeanClaude Kaufmann encontram-se, no entanto, no desejo de mostrar as maneiras concretas através das quais as disposições são transmitidas no cotidiano. Afinal, é próprio dos conceitos sociológicos "testar empiricamente uma orientação de pesquisa" (Corcuff, 1999, p. 104). Para ambos, essa é a maior falha da teoria de Bourdieu: o habitus, onipresente e onipotente, está ao mesmo tempo em toda e em nenhuma parte e não se sabe como ele é transmitido. Se para Lahire (1999), é fundamental que esse conceito retórico seja submetido à prova das pesquisas empíricas, Jean-Claude Kaufmann (2001) vai mais longe e propõe sua substituição pelo conceito de hábito, na medida em que esse último se presta mais acuradamente a tal teste. 
Outro ponto de similaridade entre as duas teorias é o lugar da reflexividade na prática cotidiana. Enquanto, para Bourdieu, o habitus configurava estruturas inconscientes ou não-conscientes, Lahire e Kaufmann vêem as ações humanas impregnadas em graus diversos pela reflexividade. Mas se Kaufmann segue Leroi-Gourhan (1965) quando diz que as cadeias operatórias que levam à prática misturam responsabilidade do sujeito e determinações sociais por vezes em proporções destinadas apenas a retificar o sentido da ação, Lahire (1995) mostra que existe reflexividade no próprio seio das ações mais cotidianas e banais - como, por exemplo, a relação com a escrita e a ordem gramatical, que se transmite através das listas de compra ou da organização mais ou menos planificada das tarefas diárias.

Seja através da construção de uma sociologia das propriedades disposicionais e contextuais, seja mediante a construção de uma sociologia do indivíduo enquanto processo, estes dois autores partem do trabalho já efetuado por Pierre Bourdieu. Desse ponto de vista, a cultura geral, sociológica e filosófica de que dispõem é um de seus capitais mais importantes nesta luta.

\section{0 conceito de campo}

Gisèle Sapiro, por sua vez, parte do conceito de campo - conceito igualmente central da teoria de Bourdieu e, dentro de sua coerência interna, talvez mais abrangente do que o habitus, na medida em que este é estruturado por aquele.

Certos setores de atividade podem ser perfeitamente analisados por esse conceito, na medida em que se enquadram nas propriedades definidas por Bourdieu para a constituição desses microcosmos sociais de essência relacional. É o caso das atividades literárias e intelectuais, cujo paradigma Bourdieu traçou em seu livro Les règles de l'art. Génèse et structure du champ littéraire (1992). Outros setores sociais, tratados freqüentemente em artigos da Actes de la Recherche, prestam-se igualmente a esse marco de análise: o cam- po acadêmico, da edição, da alta costura, do jornalismo, das grandes écoles ${ }^{15}$ etc.

Gisèle Sapiro escolheu como objeto de análise o campo literário francês sob a ocupação alemã (19401944) e no período da pós-guerra. Ela o trata em grande parte - sobretudo no que se refere à história estrutural do período - dentro da teoria dos campos (Sapiro, 1999). ${ }^{16}$ Seu objetivo era "compreender as condutas políticas dos escritores franceses durante a ocupação alemã à luz das lógicas próprias ao mundo das letras" (Sapiro, 2001, p. 88). Mas Gisèle Sapiro foi mais longe do que seu orientador, em vários momentos do seu trabalho, configurando um real avanço dentro da teoria dos campos. Em primeiro lugar, ela se opôs à tendência de Bourdieu de diferenciar progressivamente as esferas de atividade - como a esfera política e a esfera literária - mostrando que "uma mesma ação pode-se inscrever em duas esferas distintas" e que existem "zonas de interseção e de superposição" (Sapiro, 2001, p. 89). Em segundo lugar, ela buscou conjugar a teoria de Bourdieu com um marco teórico interacionista, sobretudo quando dissociou "a significação social das condutas e das obras das intenções e dos sentidos visados ou declarados pelos autores", tomando cuidado em separar as "declarações de intenção e as justificações letradas dos atores [...] do sentido que a comunidade dos pares lhes dava no mesmo momento" (Sapiro, 2001, p. 90). Essa mesma abordagem foi utilizada quando ela estudou a constituição das redes informais e de sua progressiva institucionalização. Em terceiro lugar, sua obra mostrou que os silêncios, as omissões e as abstenções são tão ou mais significativos do que as ações efetivamente realizadas. Em quarto lugar, ela realizou um estudo prosopo-

${ }^{15}$ Estabelecimentos de ensino superior de elite na França, tais como a Ecole Nationale des Ponts et Chaussées, a Ecole Polytechnique, a Fondation Nationale de Sciences Politiques, a Ecole Normale Supérieure.

${ }^{16} \mathrm{O}$ livro citado foi escrito a partir de sua tese de sociologia na EHESS, orientada por Pierre Bourdieu, em 1994, intitulada Complicités et anathèmes en temps de crise: modes de survie du champ littéraire et de ses institutions, 1940-1953. 
gráfico de dois autores de habitus semelhante que assumem posições opostas no campo (Sapiro, 1996b). Em quinto e último lugar, ela mostrou como certas manifestações de autonomia dos campos podem ocultar por vezes intenções e influências heteronômicas (Sapiro, 1996a, p. 5-6).

Na verdade, este último achado é o que mais chama atenção em sua obra. Vários autores consideram que as principais questões colocadas pela teoria dos campos são ligadas ao grau de autonomia relativa que lhes empresta Pierre Bourdieu e como isso poderia manifestar-se concretamente. Lahire (1999, p. 24) detecta nas obras de Bourdieu uma interrogação quanto à existência de uma "boa" ou de uma "má” autonomia. Já Gisèle Sapiro (1999) detém-se na interação entre lógicas autônomas e lógicas heterônomas - sobretudo quando o campo atravessa momentos de crise - e faz uma bela demonstração de sua mútua correlação.

Deve-se, no entanto, notar que Sapiro subordinou o quadro interacionista ao quadro teórico subjacente à história estrutural. Segundo a mesma e, nesse ponto, ela seguiu a linha de Bourdieu, embora fosse mais flexível do que ele -, "o estudo das interações deve ser reinserido em uma análise estrutural das relações objetivas, identificáveis através das propriedades sociais dos agentes e das instituições" (Sapiro, 2001, p. 95).

Seu trabalho é considerado "uma das realizações recentes mais bem-sucedidas em matéria de sociologia histórica dos intelectuais". Segundo Laurent Jeanpierre (2001, p. 70-71), “a Guerra dos escritores aceita o desafio das objeções dirigidas nestes últimos anos à sociologia de Bourdieu: àqueles que criticavam a teoria dos campos porque não dava conta das evoluções históricas, Gisèle Sapiro demonstra o interesse de uma história estrutural. Ao consagrar um capítulo à comparação das trajetórias de dois escritores católicos [...], ela submete essa teoria à prova do singular".

No entanto, por mais fértil que seja a teoria dos campos, certos autores pensam que ela não cobre todos os registros sociais da ação. Segundo Lahire (1999, p. 32), "a redução de todos os contextos sociais a campos relativamente autônomos seria uma generalização abusiva". Pelos exemplos citados no início dessa seção, pode-se ver que os campos correspondem melhor às atividades profissionais de prestígio, nas quais a concorrência é estimulada por uma luta maior ou menor para a conquista de um capital simbólico específico. Dada essa definição, o conceito elimina "as populações sem atividade profissional, inclusive uma maioria de mulheres". Essa teoria ignora ainda o fato de que os atores que exercem uma profissão não se reduzem a ela. Eles inscrevem-se “em outros marcos sociais, privados ou públicos, duráveis ou efêmeros" - como, por exemplo, a família - e freqüentam campos diversos com posições diferentes: produtores, consumidores, espectadores etc. (Lahire, 1999, p. 35-37).

Mas Sapiro é ainda jovem e começou há pouco tempo sua carreira. ${ }^{17}$ Contrariamente a outros pesquisadores do Centre de Sociologie Européenne, já em seu primeiro e ainda único livro, ela dá sinais de avançar, no sentido de explorar os não-ditos da teoria de Bourdieu e de buscar completá-la com outras abordagens. Nesse sentido, ela ainda não teve tempo de depurar seu pensamento, de traçar um programa de pesquisa que seja verdadeiramente seu. Dada sua proximidade com Bourdieu, talvez tenha sido ela quem mais sofreu, mas, paradoxalmente, quem mais ganhou com sua morte.

\section{Crítica, autocrítica e reflexividade}

Para avançar no sentido de uma sociologia decididamente contemporânea, é preciso que os candidatos à sua sucessão sejam capazes de ultrapassar em sua prática os limites da cultura acadêmica francesa e estabelecer um verdadeiro debate com seus pares, em torno do melhor caminho para alcançar a articulação dos vários níveis de análise da realidade.

${ }^{17}$ Lahire publicou seu primeiro livro em 1993. Depois dessa data, escreveu outros quatro e organizou duas obras coletivas. Kaufmann começou com La Trame conjugale em 1992 e publicou depois disso mais seis livros. 
A sociologia não é a única disciplina na França a padecer da ausência de tal debate. Jacques Bouveresse (1984, p. 45) aponta para o definhamento da tradição crítica da filosofia, tradição que ele considera absolutamente normal e indispensável a qualquer disciplina. Trata-se, pois, de mudar um habitus global da universidade francesa - o que não é simples. É interessante notar, quanto a isso, que o único debate entre dois pesquisadores franceses, com direito a resposta, a que tive acesso durante a pesquisa para escrever este artigo, teve como suporte uma revista anglo-saxã. ${ }^{18}$

A falta de abertura em direção ao debate acadêmico foi uma das críticas mais virulentas que os dois primeiros autores tratados neste artigo fizeram a Pierre Bourdieu. Jean-Claude Kaufmann (2001, p. 132) diz que ele "ignora seus contemporâneos disciplinarmente próximos, quando eles surgem, considerando-os como rivais potenciais ou como gentinha da pesquisa, e recusa de maneira epidérmica a crítica de suas teses". Lahire (1999, p. 6) diz que "se Bourdieu vê apenas 'inimigos' que o 'atacam' e poucos 'adversários' verdadeiros que fariam o trabalho necessário para lhe opor uma 'refutação', é porque ele se recusa a reconhecer os adversários e permanece surdo a toda refutação".

Se ambos têm razão, sobretudo no que se refere ao desenvolvimento cumulativo da ciência, essas posições contêm uma parte de amargura por não terem conseguido romper o silêncio de Bourdieu - o que os faria se situar no mesmo patamar intelectual que ele e de ressentimento, na medida em que este se recusou a dar-lhes legitimidade.

Uma das características admiráveis em Bourdieu, ao contrário da maior parte dos sociólogos franceses, era sua capacidade de submeter seu próprio trabalho a uma autocrítica. Suas idéias sobre a reflexividade necessária a todo pesquisador são anteriores aos trabalhos de Giddens $(1990,1994)^{19}$ e foram

\footnotetext{
${ }^{18}$ Trata-se do debate (escrito e publicado em francês) entre
} Laurent Jeanpierre, 2001 (EHESS Marseille), e Gisèle Sapiro, 2001 (CNRS/EHESS Paris), na revista French Politics, Culture and Society.

${ }^{19}$ Essas reflexões sobre o exame autocrítico da subjetividade mais bem sistematizadas no livro Réponses; pour une anthropologie réflexive (1992), escrito em colaboração com Loïc Wacquant. As críticas que lhe são dirigidas, no entanto, levam pouco em conta esse aspecto. Não me sinto à vontade para afirmar que essa atitude se originasse no desprezo por seus contemporâneos. Posso, no entanto, atestar a força da revisão que o assisti fazer durante seu seminário de 1992 a 1993, no Collège de France, quando retomou o conjunto de sua obra para refletir sobre uma questão extremamente interessante (que não será tratada aqui, por fugir ao objeto central deste artigo): o problema da ação gratuita e desinteressada contra a lógica utilitarista. Nesse seminário, ele respondeu (como de hábito sem citar o autor) às críticas que Alain Caillé (1988) lhe tinha dirigido alguns anos antes.

No livro publicado seis meses antes de sua morte (Bourdieu, 2001), porém, sua posição parece bastante diferente. Aí, ele diz explicitamente que, se a auto-análise é necessária, ela "é apenas um ponto de partida e a sociologia do objeto que eu sou é necessariamente uma tarefa coletiva" (Bourdieu, 2001, p. 184). Mas até mesmo o que pode parecer, para algumas pessoas, o início de um processo autocrítico, no qual Bourdieu se abriria finalmente à discussão com seus pares, pode ser percebido por outras como mais uma manifestação de narcisismo, como se o próprio Bourdieu se erigisse no único sociólogo que valesse a pena objetivar. De qualquer maneira, a "indesejada das gentes" $" 20$ impediu para sempre de ver em que sentido evoluiria sua atitude.

O que seria mais importante, no caso, é que os membros da comunidade sociológica francesa que aprovaram as críticas feitas a Bourdieu sob esse aspecto sejam coerentes com essa nova posição e ado-

do pesquisador são, no entanto, anteriores aos dois autores anteriormente citados. Alguns trabalhos menos conhecidos no Brasil o provam, como os de Alan Peshkin (1982) e de Margaret LeCompte (1987).

${ }^{20}$ É assim que Manuel Bandeira chama a morte, em seu poema "Consoada". 
tem uma prática de diálogo que contribua ao avanço coletivo da disciplina.

\section{Conclusão}

Tecidas as considerações anteriores, cabe-me agora tentar responder às questões colocadas, de maneira explícita ou implícita, neste artigo. Elas são de ordens diversas: as que tratam propriamente da sucessão de Pierre Bourdieu, ligadas à organização do campo da sociologia na França; as que se referem à influência de Bourdieu no Brasil, particularmente ao campo da educação; e, finalmente, as que introduzem questões gerais no campo das ciências sociais.

A primeira ordem de questões resume-se a saber qual dos autores mencionados adquiriu suficiente legitimidade dentro do campo da sociologia francesa para reivindicar a posição aspirada. Através dos fatos descritos, mostrei que cada um dos pretendentes parte de um conceito central para construir uma teoria mais ampla em termos de explicação social. Uma análise do campo em que se inserem leva a verificar que, depois do enfraquecimento dos paradigmas dominantes em meados dos anos de 1980, nenhuma das diversas tentativas de proclamação de novos paradigmas, tanto na França quanto nos demais países, conseguiu o consenso necessário para se impor (Xavier de Brito \& Leonardos, 2001). Nessa conjuntura, de maneira geral, nenhum pesquisador deseja mais ser identificado como tendo feito uma adesão total e irrestrita a uma ou outra teoria ou modelo. A principal divergência entre os diferentes autores reside no peso que cada qual atribui a cada elemento contraditório - social ou individual, teoria ou trabalho de campo, quantitativo ou qualitativo em suas diversas obras e também nos esforços realizados em direção a uma síntese - quando se considera que uma síntese é possível. Esse trabalho epistemológico requer, no entanto, uma sólida e extensa cultura filosófica - qualidade que nem todos mostram possuir.

Nesse estado do campo - para utilizar a terminologia de Bourdieu - parece óbvio que nenhum investigador pode congregar um consenso. Morin (1996) diz que, em toda comunidade, há que considerar tanto o lado consensual, quanto o lado das "oposições e conflitos pessoais, que podem resultar dos humores, das antipatias, das ambições e das frustrações", ou seja, não se trata de escolher entre gemeinschaft e gesellschaft (Tönnies, 1977) mas de reconhecer que toda realidade social conjuga elementos de uma e de outra. O que se tem constatado é que cada um dos três autores mencionados desfruta de maior prestígio dentro de sua comunidade de eleição ou de persuasão (Xavier de Brito \& Leonardos, 2001). O próprio Bourdieu reconhecia a dificuldade de ultrapassar tais fronteiras, na medida em que as trajetórias individuais são ligadas ao estado do campo nas diversas conjunturas. Assim, Gisèle Sapiro tem maior legitimidade junto aos que participaram de uma ou de outra maneira da equipe de Bourdieu; Bernard Lahire nos meios da sociologia da educação e Jean-Claude Kaufmann entre os sociólogos da família. Somente o futuro indicará quem assumirá efetivamente a sucessão de Pierre Bourdieu - sem excluir a possibilidade de que um azarão entre no páreo.

A segunda ordem de questões refere-se à influência de Bourdieu no Brasil, particularmente na área das pesquisas em educação. Vivendo há cerca de 30 anos na França, hesitei antes de abordar essa questão. Creio, no entanto, que os contatos que mantenho com meu país são ativos o bastante para me permitir algumas reflexões a este respeito. ${ }^{21}$

Por um lado, parece-me que os conceitos de Bourdieu são aplicados de maneira indiscriminada nos trabalhos em educação. Talvez isso se deva à "pobreza teórico-metodológica" diagnosticada por Alves-Mazzotti (2001) nas pesquisas dessa área com poucas e honrosas exceções. Essas lacunas de formação não são, no entanto, exclusivas ao Brasil, mas à área - na qual uma pluridisciplinaridade com freqüência mal compreendida e mal construída não

\footnotetext{
${ }^{21}$ Peço de antemão perdão aos meus colegas e leitores caso
} alguma dessas observações se revele inexata e solicito que me enviem seus argumentos e objeções às minhas análises ao $e$-mail marcado no final deste artigo. 
permite o pleno domínio de nenhum campo disciplinar. Assim, as sciences de l'éducation na França e os educational studies nos Estados Unidos partilham essas ambigüidades com os pesquisadores brasileiros em educação.

Por outro lado, essa aplicação nem sempre obedece ao desejo do próprio Bourdieu de ver respeitada uma homologia entre os diferentes objetos sobre os quais se aplica sua teoria. Se os conceitos de Bourdieu encontram aplicação mais rigorosa nos estudos feitos sobre os intelectuais (Miceli, 2001), é porque, apesar das diferenças de historicidade constatadas em certos campos, ${ }^{22}$ esse grupo apresenta homologias mais fortes com o grupo francês similar do que com outros setores da sociedade brasileira.

Contrariamente ao que muitos afirmam, Bourdieu não é um sociólogo da educação. Não obstante, ele tem um pensamento forte sobre o processo educacional, que não se pode reduzir a uma aplicação mecânica de conceitos isolados. A atualidade de alguns temas desenvolvidos por ele convém à análise de certas questões constantemente presentes nos estudos em educação no Brasil. Por exemplo, a reflexão sobre igualdade formal, igualdade real e desigualdade contida em "L'école conservatrice en France" (Bourdieu, 1966) poderia esclarecer alguns pontos do debate brasileiro sobre a escola pública; a problemática presente sobretudo em "Le titre et le poste" (Bourdieu \& Boltanski, 1975) sobre a escola como uma instituição essencialmente produtora de qualificações - e não transmissora de conteúdos e de saberes, como ela mesma se proclama - poderia suscitar reflexões sobre seu papel em uma sociedade em que grande parte dos habitantes não está inserida no sistema formal. Por sua vez, "Avenir de classe et causalité du probable" (Bourdieu, 1974) ajuda a compreender o efeito potencializador de um tipo de capital sobre o outro dentro de uma mesma situação, o que contribui a explicar porque as escolas públicas melhoram quando as famílias de classe média voltam a freqüentá-las, ao dei-

${ }^{22}$ Refiro-me à objeção de Luciano Martins (1987), no que se refere à aplicação do conceito de campo à universidade brasileira. xar o sistema privado em razão de sua carestia; a visão de Bourdieu sobre a relação entre trajetória individual e estruturas sociais explicitada em "L'illusion biographique" (1986), assim como a interação entre educação, socialização e estilo de vida, feita através do conceito de habitus, poderia contribuir à interpretação de trajetórias de ascensão ou descenso social e assim por diante.

Howard Becker ${ }^{23}$ disse, durante conferência na Universidade de Jussieu (Paris VII), em 1990, que um verdadeiro sociólogo pode aplicar sua teoria a qualquer objeto, seja ela original, formada de recortes de outras teorias coerentes entre si ou tomada de outro autor em sua integralidade; esse é um critério essencial para a prática sociológica. Seremos nós capazes de adotar outra definição de "realidade" que não segmente a sociedade? As sociologias especializadas tornaram-se tão naturais para nós que é raro ver os sociólogos conceberem sua disciplina de outra forma que não seja a cortada em fatias. Bourdieu (1987), no entanto, já alertava que a familiaridade com uma tradição acadêmica pode ser tão perigosa para a ciência quanto a influência do senso comum. A era das sociologias especializadas poderia talvez ter sido colocada em questão mais cedo, se os movimentos internos ao campo acadêmico não fizessem que muitos pesquisadores e professores, preocupados em excesso com sua carreira e/ou sua notoriedade, preferissem ser "o primeiro em Roma do que o segundo no mundo" (Singly, 2002b).

Os pesquisadores em educação do Brasil teriam muito a ganhar se buscassem perceber a extensão e a complexidade da obra de Bourdieu, seu constante trabalho de reflexão para compreender a sociedade em

${ }^{23}$ Howard Becker é um sociólogo americano que faz parte da segunda geração da Escola de Chicago. Escreveu, entre outros, The career of the Chicago public teacher (sobre as carreiras dos professores primários da cidade de Chicago), Boys in white (uma pesquisa sobre os estudantes de medicina, em colaboração com Blanche Geer), Outsiders (um estudo sobre a sociologia do desvio), Tricks of the trade (livro metodológico sobre as astúcias do trabalho de campo). 
que vivia, assim como a necessidade de não separar visão objetiva e visão subjetiva da realidade, presente nos trabalhos atuais dos que efetuaram uma crítica respeitosa de sua obra.

Justamente esse pensamento introduz a terceira ordem de questões - aquelas para as quais não tenho resposta individual, pois fazem parte das discussões que se travam no campo mais vasto das ciências humanas e sociais. Uma das mais importantes refere-se à velha discussão sobre a necessidade de uma ruptura epistemológica entre o senso comum e a ciência. Desse ponto de vista, desde que escreveu junto com JeanClaude Passeron e Jean-Claude Chamboredon o Métier de sociologue (1967), Bourdieu sempre se pronunciou claramente pela necessidade de se construir o objeto de maneira rigorosa, pois só uma certa distância para com o senso comum permitiria a obra científica. No momento atual, a sociologia francesa atravessa um período em que as duas posições estão representadas no campo - de maneira explícita, mas por vezes também de maneira insidiosa, não declarada. No que se refere aos autores que evocamos neste artigo, apenas Luc Boltanski (1990) declara renunciar a fazer uso de uma capacidade de análise radicalmente diferente daquela dos atores que entrevista e que lhe daria uma posição de poder. Os demais, de acordo com Kauffman (2001, p. 132), pensam que "o pesquisador deve se livrar do poder do senso comum, sobretudo da visão reflexiva e autosuficiente do sujeito".

O poder, entretanto, existe independentemente do comportamento do pesquisador, na medida em que faz parte das próprias representações do ator social. O que é preciso então é manifestar uma atitude de respeito para com os sujeitos de nossas pesquisas - não um falso respeito que se manifeste apenas através de um discurso demagógico, mas a consideração que se traduz através de práticas concretas, como a devolução das dádivas que eles nos fazem no decurso da pesquisa (Xavier de Brito, 1994; Xavier de Brito \& Vasquez, 1999).

Apesar das aparências de que existe uma grande resistência à mudança dentro do campo da sociologia - sobretudo no que se refere a discussões que parecem eternas, como as que opõem redução e comple- xidade, macro e micro, social e individual, teoria e empiria, agente e ator, objeto e sujeito, quantitativo e qualitativo, entre outras -, penso que essa disciplina se encaminha, como o preconizava Elias (1983), para a superação da existência de um abismo estático e infranqueável entre duas polaridades.

Será a sociologia capaz de enfrentar o desafio da complexidade? Que imagens ou recursos científicos serão capazes de captá-la? Para o grupo etário a que pertenço, a atração por uma representação binária faz parte das disposições geracionais (Xavier de Brito \& Leonardos, 2001). Devemos, no entanto, tomar consciência das limitações acadêmicas e éticas dentro das quais fomos socializado(a)(s) e fazer um esforço no sentido de desaprender as categorias mais familiares, as práticas mais tradicionais da ciência. O grande desafio recairá certamente sobre os ombros da próxima geração de pesquisadores, suscetível de ter recebido influências dos dois lados e criada dentro de um espírito de maior complexidade.

ANGELA XAVIER DE BRITO é pesquisadora do Centre National de la Recherche Scientifique (CNRS), trabalhando no Centre d'Études sur les Liens Sociaux (CERLIS), e professora do Départament de Sciences de l'Education, Faculté de Sciences Humaines et Sociales de l'Université René Descartes (Paris V). Autora do livro Estudos no exterior e internacionalização das elites (no prelo) e de diversos artigos na França, no Brasil e em outros países. E-mail: axavier@paris5.sorbonne.fr

\section{Referências Bibliográficas}

ALEXANDER, Jeffrey, (2000). La réduction. Critique de Bourdieu. Paris: Éditions du Cerf, coll. Humanités.

ALVES-MAZZOTTI, Alda Judith, (2001). Relevância e aplicabilidade da pesquisa em educação. Cadernos de Pesqui$s a, \mathrm{n}^{\circ} 113$, p. 39-50, jul.

BATEMAN-NOVAES, Simone, (1986). Le sociologue et l'individuel. Bulletin de Psychologie, v. XXXIX, n 337, p. 827-830.

BOLTANSKI, Luc, (1990). L'amour et la justice comme compétences. Trois essais de sociologie de l'action. Paris: Métailié. 
BOURDIEU, Pierre, (1966). L'école conservatrice, les inégalités devant l'école et devant la culture. Revue Française de Sociologie, v. VII, n 3, p. 325-347.

, (1974). Avenir de classe et causalité du probable. Revue Française de Sociologie, v. XV, n 1, p. 3-42. , (1980). Le sens pratique. Paris: Minuit. , (1984). Homo Academicus. Paris: Minuit.

, (1986). L'illusion biographique. Actes de la Recherche en sciences sociales, $\mathrm{n}^{\circ} 62 / 63$, p. 53-76.

, (1987). Choses dites. Paris: Minuit.

, (1988). L'ontologie politique de Martin Heidegger.

Paris: Minuit.

, (1992-1993). Séminaire du Collège de France.

, (1992). Les règles de l'art. Génèse et structure du champ littéraire. Paris: Seuil.

, (2001). Science de la science et reflexivité. Paris:

Raisons d'Agir.

BOURDIEU, Pierre, BOLTANSKI, Luc, (1975). Le titre et le poste. Actes de la Recherche en Sciences Sociales, $\mathrm{n}^{\circ} 2$.

, (1976). La production de l'idéologie dominante.

Lieux neutres et lieux communs. Actes de la Recherche en Sciences Sociales, $\mathrm{n}^{\circ}$ 2/3.

BOURDIEU, Pierre, CHAMBOREDON, Jean-Claude, PASSERON, Jean-Claude, (1967). Le métier de sociologue; préalables épistémologiques. Paris/La Hague: Mouton.

BOURDIEU, Pierre, WACQUANT, Loïc, (1992). Réponses. Pour une anthropologie réflexive. Paris: Seuil.

, (1994). Raisons Pratiques. Sur la théorie de l'action.

Paris: Seuil.

BOUVERESSE, Jacques, (1984). Le philosophe chez les autophages. Paris: Minuit.

CAILLÉ, Alain, (1988). Esquisse d'une critique de l'économie générale de la pratique, Cahiers du LASA, n 8/9.

CHAPOULIE, Jean-Michel, (1984). E. C. Hughes et le développement du travail de terrain en France. Revue Française de Sociologie, v. 25, $\mathrm{n}^{\circ} 4$, p. 582-608.

(2000). Le travail de terrain et l'observation.

Introduction au numéro spécial sur Travail de terrain et observation des comportements. Sociétés contemporaines, n 40, p. 9-27.
(2001). La tradition sociologique de Chicago, 1892-

1961. Paris: Seuil.

COLLET, Beate, (1997). Étude anthropologique dans un lycée de la banlieue parisienne. Éducation et sociétés plurilingues, $\mathrm{n}^{\circ} 3$, p. 59-68, dez.

CORCUFF, Philippe, (1999). Le collectif au défi du singulier: en partant de l'habitus. In: LAHIRE, Bernard, (ed.). Le travail sociologique de Pierre Bourdieu, dettes et critiques. Paris: La Découverte, p. 95-120.

, (2002). Respect critique. Sciences Humaines, $\mathrm{n}^{\circ}$ spécial sur L'œuvre de Pierre Bourdieu, p. 64-71.

DUBET, François, (1998). Le sociologue de l'éducation. Magazine Littéraire, $\mathrm{n}^{\circ} 369$, p. 45-47, octobre.

ELIAS, Norbert, (1983). Engagement et distanciation. Paris: Fayard. , (1985). La société de cour. Paris: Flammarion, coll. Champs. , (1991). La société des individus. Paris: Fayard.

GIDDENS, Anthony, (1990). The consequences of modernity. Cambridge: Polity Press.

, (1994). Beyond left and right, the future of radical politics. Cambridge: Polity Press.

HESS, Rémi, XAVIER DE BRITO, Angela, (1999). Préface. In: VASQUEZ, Ana, MARTINEZ, Isabel, (ed.). Recherches ethnographiques en Europe et en Amérique du Nord. Paris: Anthropos, p. V-XII.

JEANPIERRE, Laurent, (2001). Politiques de l'écrivain ou politiques de l'écriture?. French Politics, Culture and Society, v. $19, \mathrm{n}^{\circ} 1$, p. $88-97$, spring.

KAUFMANN, Jean-Claude, (2001). Ego. Pour une sociologie de l'individu. Une autre vision de l'homme et de la construction du sujet. Paris: Nathan.

LAHIRE, Bernard, (1995). Tableaux de familles. Heurs et malheurs scolaires en milieux populaires. Lille: PUL, coll. Sociologie. (1998). L'homme pluriel. Les ressorts de l'action. Paris: Nathan.

, (ed.) (1999). Le travail de Pierre Bourdieu, dettes et critiques. Paris: La Découverte.

, (2002a). Portraits sociologiques. Dispositions et variations individuelles. Paris: Nathan, coll. Essais et recherches. 
Rei morto, rei posto?

, (ed.) (2002b). À quoi sert la sociologie? Paris: La Découverte, coll. Le laboratoire des sciences sociales.

LECOMPTE, Margaret, (1987). Bias in biography. Bias and subjectivity in ethnographic research. Anthropology and education quarterly, v. $18, \mathrm{n}^{\circ} 1$, mars.

LE MONDE, 25 de janeiro de 2002. Entrevistas com Francine Muel-Dreyfus, Luc Boltanski, Michel Pinçon, Monique PinçonCharlot por ocasião da morte de Pierre Bourdieu.

LEROI-GOURHAN, André, (1965). Le geste et la parole. Tome II, La mémoire et les rythmes. Paris: Albin Michel.

MARTINS, Luciano, (1987). A gênese de uma intelligentsia; os intelectuais e a política no Brasil, 1920-1940. Revista Brasileira de Ciências Sociais, v. 2, n 4 , p. 65-87.

MICELI, Sérgio, (2001). Intelectuais à brasileira. São Paulo: Companhia das Letras.

MORIN, Edgar, (1996). O problema epistemologico da complexidade. Mem Martins (Portugal): Publicações Europa-América. (2001). L'identité humaine. La méthode, v. 5. L'humanité de l'humanité. Paris: Seuil.

MUEL-DREYFUS, Francine, (1996). Vichy et l'éternel féminin. Contribution à une sociologie politique de l'ordre du corps. Paris: Seuil.

PESHKIN, Alan, (1982). The researcher and subjectivity. Reflections on an ethnography of school and community. In: SPINDLER, Georges, (ed.). Doing the ethnography of schooling. New York, Winston \& Rinehart, p. 48-65.

PINÇON, Michel, PINÇON-CHARLOT, Monique, (1989). Dans les beaux quartiers. Paris: Seuil.

RUDE-ANTOINE, Edwige, (1999). Trajectoires familiales, transformations des rôles et des statuts. In: DEWITTE, Philippe, (ed.). Immigration et intégration, l'état des savoirs. Paris: La Découverte, p. 196-204

SAPIRO, Gisèle, (1996a). La raison littéraire. Le champ littéraire français sous l'Occupation (1940-1944). Actes de la Recherche en sciences sociales, $\mathrm{n}^{\circ} 111-112$, p. 3-35, mars.

, (1996b). Salut littéraire et littérature du salut. Deux trajectoires de romanciers catholiques, François Mauriac et Henry Bordeaux. Actes de la Recherche en sciences sociales $\mathrm{n}^{\circ} 111-112$, p. 36-58, mars.
(1999). La guerre des écrivains (1940-1953). Paris:

Fayard.

(2001). Réponse (à Laurent Jeanpierre). French politics, culture and society, v. 19, $\mathrm{n}^{\circ} 1$, p. 70-81, spring.

SINGLY, François de, (1996). L'appropriation de l'héritage culturel. Lien social et politiques, ${ }^{\circ} 35$, p. 153-166.

, (2002a). Une autre façon de faire de la théorie. Sciences Humaines, n spécial sur L'œuvre de Pierre Bourdieu, p. 90-95. (2002b). La sociologie, forme particulière de conscience. In: LAHIRE, Bernard, (ed.). À quoi sert la sociologie? Paris: La Découverte, p. 7-42.

TÖNNIES, Friedrich, (1977). Communauté ou société. Catégories fondamentales de la sociologie pure. Paris, La bibliothèque du CEPL.

TOURAINE, Alain, (2002). Le sociologue du peuple. Entrevista concedida a J.-F. Dortier para Sciences Humaines, $\mathrm{n}^{\circ}$ spécial sur L'œuvre de Pierre Bourdieu, p.101-103.

VASQUEZ-BRONFMAN, Ana, (2000). Élaborer de nouveaux concepts pour mieux comprendre une réalité sociale qui change. In: TANON, Fabienne, (ed.). Jeunes en rupture scolaire. Du processus de confrontation à celui de remédiation. Paris: l'Harmattan, p. 31-58.

VERDÈS-LEROUX, Janine, (1998). Le savant et la politique. Essai sur le terrorisme sociologique de Pierre Bourdieu. Paris: Grasset.

XAVIER DE BRITO, Angela, (1994). La construction de la relation entre le chercheur et son objet: une interprétation à la lumière de la théorie du don. Revue du Mauss, $\mathrm{n}^{\circ} 4,2^{\circ}$ semestre.

XAVIER DE BRITO, Angela, VASQUEZ, Ana, (1999). Image as a symbolic gift. In: WALFORD, G., MASSEY, A., (ed.). Studies in educational ethnography, vol. 2. Explorations in methodology. London: Jai Press, p. 109-125.

XAVIER DE BRITO, Angela, LEONARDOS, Ana Cristina, (2001). A identidade das pesquisas qualitativas. Construção de um quadro analitico. Cadernos de Pesquisa, n 113, p. 7-38, jul.

XAVIER DE BRITO, Angela, (no prelo). L'habitus de migrant. Saisir le quotidien des personnes en déplacement. (Artigo submetido à publicação nas revistas Lien Social et Politiques e Sociétés Contemporaines). 


\section{Resumos/Abstracts}

Angela Xavier de Brito

Rei morto, rei posto? As lutas pela sucessão de Pierre Bourdieu no campo acadêmico francês

A morte de Bourdieu, que todos consideravam o maior sociólogo da língua francesa, deixou um grande vazio intelectual, difícil de ser preenchido.

Neste artigo, em um primeiro momento, a autora situa, para fins analíticos, os processos pelos quais a transmissão de sua herança tem sido feita, na esfera institucional, e as posições intelectuais, de seus principais seguidores, nela presentes. As oportunidades de aspirar a esta herança parecem estar divididas entre três candidatos:

Bernard Lahere, Jean-Claude

Kaufmann e Gisèle Sapiro, autores que estão em diferentes etapas de suas carreiras e os únicos a oferecer uma crítica respeitosa da teoria de Bourdieu e a propor sua extensão. Os primeiros dois autores partem do conceito de habitus e a última de campo. Conclui comentando como o desdobramento do pensamento de Bourdieu sobre a educação pode contribuir para o debate acadêmico brasileiro nessa área.

Palavras-chave: Pierre Bourdieu, sociologia da educação, campo educacional francês.

The King is dead, long live the King? The struggle to inherit Pierre Bourdieu's position in the French academic field

Bourdieu's death has left a great intellectual void in the French sociological community. This article intends, first of all, to state the struggles in the academic field that have followed this event. In order to show the processes by which the transmission of his inheritance has been carried out, we must distinguish the institutional assets, which could be bequeathed by Bourdieu himself to his followers, from the intellectual positions. The chances to aspire to this main inheritance seem to be divided between three candidates Bernard Lahire, Jean-Claude Kaufmann and Gisèle Sapiro authors who are at different stages of their careers. They seem to be the only ones to make a respectful critique of Bourdieu's theory and to propose its full extension. The first two authors begin from the concept of habitus, the last one from that of field. Last but not least, I intend to make some comments on how Bourdieu's theory can nourish the Brazilian academic debate in this domain.

Key-words: Pierre Bourdieu, educational sociology, french academic field.

Jorge Larrosa Bondía

Notas sobre a experiência e o saber de experiência

Propõe pensar-se a educação a partir do par experiência/sentido, contrapondo-se ao modo de pensar a educação como relação entre ciência e técnica, ou entre teoria e prática. Para tanto, explora o significado das palavras ex- periência e sentido. Quanto à primeira, critica o excesso de informação e a obrigatoriedade de ter opinião, posturas que estão na base da "aprendizagem significativa”. Critica também o excesso de trabalho, que não permite a experiência, e a própria relação trabalho/experiência. Quanto ao sentido, explora-o a partir do sujeito da experiência, definido não por sua atividade, mas pela abertura para ser transformado pela experiência - território de passagem, submetido a uma lógica da paixão. Afirma que o saber da experiência se dá na relação entre o conhecimento e a vida humana, singular e concreta.

Palavras-chave: experiência, saber de experiência, experiência/sentido.

\section{Notes on experience and the} knowledge of experience The text proposes to think education taking the pair experience/sense as its starting point, in opposition to that way of thinking education as a relation between science and technology or between theory and practice. To this end, it explores the meaning of the words experience and sense. With respect to the first, it criticises the excess of information and the obligation of having an opinion, postures which are at the base of "significant learning". It also criticises the excess of work which does not allow experience and the very relation work/experience. With relation to sense, this is explored on the basis of the subject of the experience, defined 